\title{
Research of vibroacoustic influence on flotation microplastic
}

\author{
Mikhail Ivanov*, Anastasiia Soloveva \\ B auman M oscow State Technical U niversity, 2-ya B aumanskaya U litsa, 5/1, 105005, M oscow,R ussia
}

\begin{abstract}
The paper studies the effect of the vibration on the flotation processes for microplastic particles (polymer particles $<5 \mathrm{~mm}$ in diameter). In recent years, the world community is facing the problem of water pollution with microplastics, which is a fundamentally new type of the particles in marine environment that has specific hydrodynamic characteristics and impairs the efficiency of existing water treatment processes. In this paper, the authors compared the classical process of pneumatic flotation with the process of pneumatic flotation with vibroacoustic effect and the positive effect of vibration influence on the efficiency of the flotation of water microplastics is shown.
\end{abstract}

\section{Introduction}

Plastic pollution is a priority problem, which has received increasing attention in the last decade [1]. Plastic products can slowly disintegrate into smaller pieces and, due to their low density, are dispersed by ocean currents and winds over aquatic and coastal environments [2]. These small polymer particles are called microplastics.

Microplastics are generally defined as solid synthetic polymer particles with a characteristic particle size of fewer than 5 millimetres, with low water solubility (less than 1 $\mathrm{mg} / \mathrm{l})$ and a low degradation rate. The following types of microplastics are distinguished by particle shape: granules, fibers, thin films, and fragments. The shape of a particle affects its hydrodynamic properties and determines the adsorption surface [3].

The emergence of microplastics has been noted all over the world [4]. Researchers have found microplastic particles in coastal oceanic zones [5], coastal sediments [6], on beaches [7], and deep in the ocean [8].

Sources of microplastics are polymer granules from production facilities and fragments formed from large polymer objects by photolysis, abrasive wear, and microbial decomposition [9], as well as primary microplastics [10] and waste from washing machines. The World Health Organization currently does not recognize microplastics itself as a direct hazard to the human body, and as a result, does not establish standards for its content in drinking water. This decision is based on studies of physical harm to the tissues of living organisms during physical interaction with microplastic particles [11].

But although there is no evidence of the danger of the polymer particles themselves to humans at the moment, it is a carrier of many other dangerous pollutants, such as heavy

* Corresponding author: mivanov@bmstu.ru 
metals [12] and pathogenic bacteria [13]. Based on the above and taking into account the durability of microplastics and their ability to travel along the food chain, the frequency of their occurrence in the aquatic environment is a global problem.

\section{Methods of wastewater purification from microplastic particles}

Research has shown that wastewater treatment technologies can remove some of the microplastics. Microplastics entering urban wastewater treatment plants are mainly composed of polyester and polyethylene. The main morphology is granular and fibrous. The pellet removal rate in wastewater treatment processes is faster than fiber. Population density, economic level, urban greening, wastewater treatment process parameters, sludge dewatering, and treatment processes can affect the concentration and behavior of microplastics at various stages of wastewater treatment. It has been proven that an increase in the level of microplastics will negatively affect the treatment of wastewater and sludge since they have an acute inhibitory effect on activated sludge flakes.

Microplastics can inhibit the production of methane in sludge and affect key enzymes and metabolic intermediates. In addition, microplastics reduce the diversity of biological communities and the abundance of key microorganisms. The adsorption of environmental micro-pollutants and the exudation of additives complicate the mechanism of the effect of microplastics on wastewater and sludge treatment.

Microplastics reduce the efficiency of wastewater and activated sludge treatment processes and increase the volume of activated sludge. If a large number of microplastics particles enter the sludge digestion system, then a longer retention time of activated sludge or a larger reservoir will be required to achieve the same treatment effect as a system without microplastics particles, which will increase the processing cost.

Therefore, internal modifications to the wastewater and activated sludge treatment processes should be made to protect the wastewater and activated sludge treatment processes. Wastewater treatment plants should avoid overloading. The hydraulic retention time can be extended to provide microplastics removal. In the future, special treatment technologies for targeted purification from microplastic particles can be developed and applied to full-scale wastewater treatment plants in order to avoid their harmful effects on wastewater and sludge treatment systems. In addition, current wastewater treatment plant processes are not specifically designed to remove microplastics and are particularly ineffective in removing fibrous particles [10].

Therefore, it is necessary to develop non-reagent methods for intensifying primary purification stages. This will make it possible to modernize the current purification devices in such a way as to reduce the load on the activated sludge treatment tanks (both in terms of the amount of microplastic entering them and the reagents absorbed on its surface) and allow the separation of microplastics along with other contaminants of petrochemical origin to simplify further possibilities their processing.

One of the effective methods of intensification of flotation is vibration action [14], the effectiveness of which is shown for the flotation of other types of pollutants [15].

\section{Materials and research methods}

The test sample was made of acrylonitrile butadiene styrene, also called ABS plastic, chemical formula $(\mathrm{C} 8 \mathrm{H} 8) \mathrm{x} \cdot(\mathrm{C} 4 \mathrm{H} 6) \mathrm{y} \cdot(\mathrm{C} 3 \mathrm{H} 3 \mathrm{~N}) \mathrm{z}$, the monomers of which and the labeling are shown in Fig. 1. Production of one kilogram of the ABS requires an equivalent of approximately $8 \mathrm{~kg}$ of oil in the form of materials and energy [16]. 


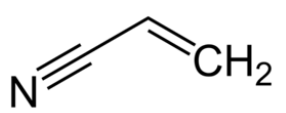

Acrylonitrile<smiles>C=Cc1ccccc1</smiles>

Styrene<smiles>C=CC=C</smiles>

1,3-butadiene

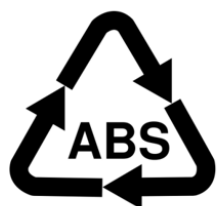

Fig. 1. Monomers that make up the ABS plastic and its labelling [17].

The choice fell on this type of plastic due to its widespread use in the automotive and light industries, as well as properties such as opacity and durability.

To simulate wear, large granules were subjected to mechanical grinding action, which resulted in the formation of microplastic particles with a characteristic size range from $1 \mathrm{~mm}$ to $1 \mu \mathrm{m}$.

To conduct tests on the effect of vibration on methods of water purification from microplastics particles, an experimental setup was created, shown in Fig. 2 and consisting of the following parts:

1.Piezoelectric accelerometers Type 4433B by Brüel \& Kjaer

2. Water with microplastic particles

3. Cylindrical column

4. Permanent Magnet Vibration Exciter - Type 4808 by Brüel \& Kjaer

5. Vibration Research VR9500 Vibration Control System

6. Power Amplifier - Type 2719 by Brüel \& Kjaer

7. Computer

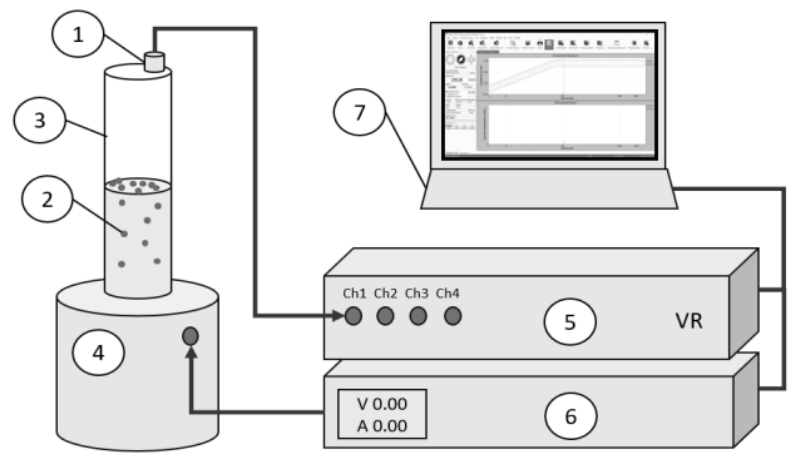

Fig. 2. Design of the experimental setup.

The most important parameters for a vibrating table are the breakpoints: limits set by the maximum acceleration, speed, and movement of the system. For the PM Vibration Exciter - Type 4808, the breakpoint table is shown in Table 1.

Table 1. Breakpoints of the PM Vibration Exciter - Type 4808.

\begin{tabular}{|c|c|c|}
\hline $\begin{array}{c}\text { Initial } \\
\text { frequency }\end{array}$ & $\begin{array}{c}\text { End } \\
\text { frequency }\end{array}$ & Amplitude \\
\hline $5 \mathrm{~Hz}$ & $63.662 \mathrm{~Hz}$ & $1 \mathrm{~mm}$ \\
\hline $63.662 \mathrm{~Hz}$ & $78.0388 \mathrm{~Hz}$ & $0.2 \mathrm{~m} / \mathrm{s}$ \\
\hline $78.0388 \mathrm{~Hz}$ & $3000 \mathrm{~Hz}$ & $10 \mathrm{G}$ \\
\hline
\end{tabular}




\section{Experimental procedure}

During the experiment, the cylindrical column (1) was filled with $350 \mathrm{ml}$ of water with the addition of $2 \mathrm{~g}$ of a microplastic sample (2). The column with water and sample was placed on a vibrating table. The system was launched through a computer with specialized software installed on it. The software pre-sets the required parameters: frequency $(\mathrm{Hz})$, the amplitude of motion $(\mathrm{mm})$, and acceleration $(\mathrm{G})$, and the system was started. Oscillatory movements from the vibrator are transferred to the reservoir through the connecting diaphragm. Vibration sensors installed on the moving part of the vibration generator allow you to monitor the progress of work and changes in the previously set parameters on the computer screen.

The first launch of the system (Experiment 1) was carried out in order to find the resonant frequencies of the system. The system was subjected to vibration from a sinusoidal signal, the dependence of the acceleration on time is shown in Figure 3 and with a frequency increasing from $50 \mathrm{~Hz}$ to $900 \mathrm{~Hz}$ at a rate of $3 \mathrm{oct} / \mathrm{min}$.

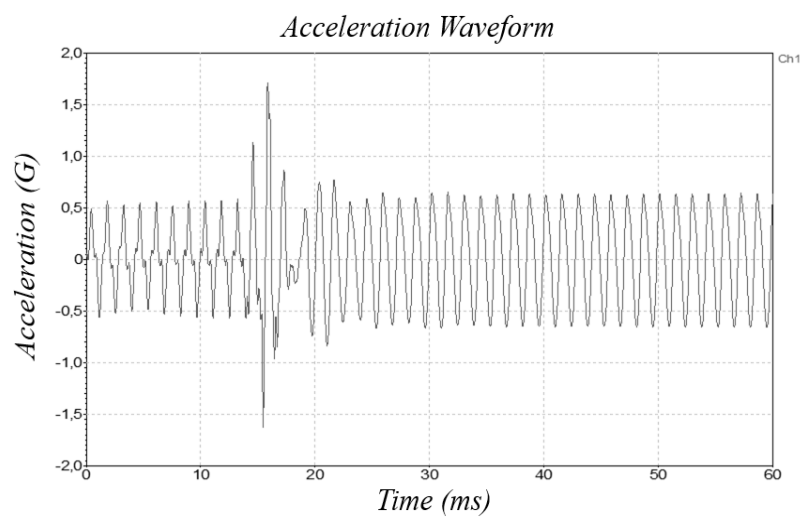

Fig. 3. Waveform of acceleration signal in experiment 1.

As a result of experiment 1 , it was found that the resonant frequency of the system is $105.5 \mathrm{~Hz}$, and also that the visible acceleration of the flotation process occurs at the resonant frequency.

During the next experiment (Experiment 2), the behavior of the system was studied in more detail during prolonged vibration action with a sinusoidal signal at a frequency of 105.5 $\mathrm{Hz}$.

A cylinder with the same amount of water and microplastic, not exposed to vibration, was used as a control sample. Experiment 2 was repeated 3 times (Experiment 2.1, experiment 2.2 , experiment 2.3) with new samples and captured on a camera for processing the results. The flotation of the coarse fraction was determined visually, the flotation of the fine fraction - by measuring the turbidity of the water on the video.

\section{Methods of wastewater purification from microplastic particles}

A coarse fraction of particles $(1 \mathrm{~mm}-0.1 \mathrm{~mm})$ floats equally quickly into the upper layer both with vibration and without it.

However, the fine fraction (less than $0.1 \mathrm{~mm}$ ) behaves like a dispersed suspension, affecting the turbidity of the water, and flotation for these particles in standing water is not observed: even when observing the sample that was not exposed, after 12 hours the turbidity did not change. For samples exposed to vibration, the turbidity to the control sample decreased, as shown in Table 2. 
Table 2. Changes in turbidity compared to the control sample.

\begin{tabular}{|c|c|c|c|}
\hline $\begin{array}{c}\text { Control } \\
\text { sample }\end{array}$ & $\begin{array}{c}\text { Experiment } \\
\mathbf{2 . 1}\end{array}$ & $\begin{array}{c}\text { Experiment } \\
\mathbf{2 . 2}\end{array}$ & $\begin{array}{c}\text { Experiment } \\
\mathbf{2 . 3}\end{array}$ \\
\hline $100 \%$ & $79 \%$ & $81 \%$ & $78 \%$ \\
\hline
\end{tabular}

Thus, vibration action at the resonant frequency made it possible to increase the efficiency of flotation of small fractions of microplastics, on average, by $20.6 \%$.

\section{Conclusion}

The microplastic pollution of water bodies is a significant global problem. Wastewater treatment plants are one of the main sources of microplastics discharge into water environments. In this regard, there is a need to increase the efficiency of water purification technologies in relation to the processes of extracting microplastics.

In this paper, a vibration method for intensifying the flotation process of the water purification from microplastics obtained from an ABS polymer was investigated. Experiments have shown that vibration does not have a significant effect on coarse particles $(>0.1 \mathrm{~mm}$ ), but increases the efficiency of flotation for a phase less than $0.1 \mathrm{~mm}$, on average, by $20 \%$.

Thus, vibration action is an effective method for intensifying the flotation treatment of wastewater from microplastic particles consisting of ABS polymers and is a promising method for further research and development.

\section{References}

1. S.M . Ladewig, S. B ao, A.T. Chow. Natural fibers: a missing link to chemical pollution dispersion in aquatic environments. Environ. Sci. Technol., 49, 12609-12610 (2015)

2. R.C. Thompson, Y. Olsen, R.P. M itchell, A. Davis, S.J. Rowland, A.W. John, D. M cGonigle, A.E. Russell. L ost at sea: where is all the plastic? Science, 304, 838, (2004)

3. Verschoor. Emission of microplastics and potential mitigation measures. A brasive cleaning agents, paints and tire wear. RIV M Report, 0026, (2016)

4. Zarfl, M. M atthies. A re marine plastic particles transport vectors for organic pollutants to the A rctic? M ar. Pollut. Bull., 60, 1810-1814, (2010)

5. M oore, C. J.; M oore, S. L.; W eisberg, S. B.; L attin, G. L.; Zellers, F. A comparison of neustonic plastic and zooplankton abundance in southern California's coastal waters. Mar. Pollut. Bull., 44, 1035-1038, (2002)

6. Ivar do Sul, J. A.; Santos, I. R.; Friedrich, A . C.; M atthiensen, A.;Fillmann, G. Plastic pollution at a sea turtle conservation area in NE Brazil: contrasting developed and undevel oped beaches. Estuarine Coasts, 34 (4), 814-823, (2011)

7. V an Cauwenberghe, L.; V anreusel, A.; M ees, J.; J anssen, C. R.M icroplastic pollution in deep-sea sediments. Environ. Pollut., 182, 495-499, (2013)

8. Cole, M.; Lindeque, P.; Halsband, C.; Galloway, T. S.M icroplastics as contaminants in the marine environment: A review.Mar. Pollut. Bull. 2011, 62 (12), 2588-2597.

9. Fendall, L. S.; Sew ell, M . A . Contributing to marine pollution by washing your face: M icroplastics in facial cleansers. M ar. Pollut. Bull., 58 (8), 1225-1228, (2009) 
10. Zhiqi Zhanga, $Y$ inguang Chen. Effects of microplastics on wastewater and sewage sludge treatment and their removal: Chemical Engineering J ournal, 382, (2020)

11. W orld Health Organization - Official Site: WHO Calls for R esearch on M icroplastics and Fight A gainst Plastic Contamination Resolutely. - URL:

https://www.who.int/ru/news-room/detail/22-08-2019-who-calls-for-more-researchinto-microplastics-and-a-crackdown-on-plastic-pollution (access date: 15.10.2019)

12. Dennis Brennecke, Bernardo Duarte, Filipa Paiva, Isabel Caçador, Joao CanningClode, Estuarine. $\mathrm{M}$ icroplastics as vector for heavy metal contamination from the marine environment, Coastal and Shelf Science. 178, 189-195, (2016)

13. M cCormick, Timothy J. Hoellein, Sherri A. M ason, J oseph Schluep, and John J. K elly. $\mathrm{M}$ icroplastic is an A bundant and Distinct M icrobial Habitat in an U rban River A manda Environ. Sci. Technol., 48, 11863-11871

14. Ivanov, M.V., K senofontov, B.S Intensification of chemical agents mixing by vibroacoustical agitation(A rticle) E cology and Industry of Russia V olume 21, 9, Pages 4-9, (2017)

15. I vanov, M. V ., K senofontov, Intensification of flotation treatment by exposure to vibration. W ater science and technology, 69(7), 1434-1439, (2014).

16. Shulpin G. These different polymers // Science and Life. -1982 . - N o. 3. - p. 8083

17. Trostyanskaya E.B., Babaevsky A.G. Plastic masses/ Chemical encyclopedia: in 5 vol. I K nunyants I.L. - M .: G reat R ussian Encyclopedia, 1992. - 639 p. 